\title{
Extrinsic feedback in martial arts training
}

\author{
Michal VÍT*, Zdenko REGULI, \& Jitka ČIHOUNKOVA \\ Faculty of Sports Studies - Masaryk University (Czech Republic) \\ International Martial Arts and Combat Sports Scientific Society - IMACSSS (Poland)
}

5th IMACSSS World Scientific Congress Abstracts, Rio Maior (Portugal), October 6-8

Section: Psychological, pedagogic and didactics in MA\&CS

Type: Oral communication

\section{Introduction}

Motor learning is a complex process, in which teacher and athletes are in the interaction. Variety of factors play important role in the process of acquiring motor skills. One of crucial factors is feedback, which is the information about the movement provided to the learner during and after a movement. Information on errors during the motion execution is especially important for the progress in the motor learning. The information may come from external or internal sources. That is why two kind of feedback are described in the kinesiology theory - intrinsic and extrinsic feedback. While intrinsic feedback come through the nervous system from muscles and joints, the extrinsic feedback is given by teacher or e.g. videotape (Hoffman, 2005). Both extrinsic and intrinsic feedback are usually used in the modern sports training. On the other hand, traditional martial arts training is typical by rigorous teaching methods such as repetition, drilling, ritualization, etc. The difference between martial arts and modern sports was described in the previews research (Cynarski, 2012; Reguli \& Vít, 2009). The traditional teaching process in martial arts proceeds according to the following scheme: teacher's technique demonstration, students' observation, repetition, verbal extrinsic feedback from teacher, drilling. There is another extrinsic feedback method used in modern sports training using video tape. We are focusing on differences between two kind of extrinsic feedback (verbal and video) in the traditional martial arts training.

\section{Methodology}

21 students in the forth semester of the study programme Special Education of Security Bodies at Masaryk University, $18(\mathrm{M})$ and $3(\mathrm{~F})$ in average age 22.1, were involved in the study. Techniques of martial art aikido were thought in one particular educational unit by using extrinsic verbal feedback from teacher firstly and afterwards by using extrinsic video feedback. After both parts of educational unit students filled in the questionnaire answering about their point of view on used feeedback methods. Dartfish software 6 was used for video extrinsic feedback and data collection (capturing video files). Questionnaire with 4 close questions using standard 5-grade Likert scales ( 1 =best, $5=$ =worst) and 1 open question was used for evaluation by students. Expert assessment using Likert scale was provided ex-post using video files. Statistical analysis of data obtained via scales and qualitative analysis of the open question were provided.

\section{Results}

There were following differences in students' perception of learning process when using extrinsic verbal and video feedback. Students evaluated their own performance more strictly by using video feedback $(M=2.81)$ in comparison with verbal feedback $(M=2.67)$. They considered the video feedback method more effective $(M=1.86)$ the verbal feedback $(M=2.10)$. Significant difference was 
in their evaluation of amusing nature of the training, where verbal feedback was less amusing $(M=2.71)$ than video feedback $(M=1.95)$. On the other hand, video feedback was in average more confusing $(\mathrm{M}=1.52)$ for students than the verbal feedback $(\mathrm{M}=1.43)$. Although average number of details, which students were focusing on were higher by verbal feedback $(M=4.29)$ than by video feedback $(M=3.52)$, we consider this difference influenced by fatigue. More important is the qualitative assessment of students' answers. The most common detail, which was in the center of students' attention by verbal feedback were basic elements of techniques such as footwork (different aspects, e.g. length of the step, side-step, direction of the step etc.), second most mentioned detail was the grasp (e.g. correctness and power in the grasp) following by disbalancing. Although footwork, grasp and disbalancing were often mentioned details in the second part of educational unit, higher variety of answer and more complex aspects (e.g., smoothness, leading the partner etc.) emerged by the video feedback.

\section{Discussion and conclusion}

Results show that use of extrinsic video feedback is considered by students more effective than extrinsic verbal feedback. Students were more critical when they saw their own execution of techniques on video. Also, use of video feedback was evaluated more amusing. We assume, there is connection between effectivity and amusing nature of training. This assertion is supported by the previews research, which showed, that positive mood influences performance of motor-skills (Anshel, 1988). On the other hand, video feedback is a method aimed for advanced students, since it requires deeper understanding of techniques, insight into principles and focus on details. That is why the video feedback could be more confusing for some students. Another advantage of the video feedback is capturing files, which could be used for the ex-post analysis by teacher or for illustrative purposes. We consider Dartfish software 6 as appropriate tool for the martial arts training using extrinsic video feedback.

\section{References}

Anshel, M. H. (1988). The effect of mood and pleasant versus unpleasant information feedback on performing a motor skill. The Journal Of General Psychology, 115(2), 117-129.

Cynarski, W. J. (2012). Martial arts phenomenon - research and multidisciplinary interpretation. Rzeszów: Wydawnictwo Uniwersytetu Rzeszowskiego.

Hoffman, S. J. (Ed.). (2005). Introduction to kinesiology: studying physical activity (2nd ed.). Champaign, IL: Human Kinetics.

Reguli, Z., \& Vít, M. (2009). Kalokagathia from Aikido Point of View. In In W. Cynarski (Ed.), Martial Arts and Combat Sports - Humanistic Outlook. Rzeszow: Rzeszow University.

Key words: Martial arts; combat sports; motor learning; extrinsic feedback. 